\title{
Intermittent vs Continuous Administration of Nerve Growth Factor to Injured Medial Septal Cholinergic Neurons in Rat Basal Forebrain
}

\author{
Kenneth E. Miller*, Gregory E. Frierdich, Robert H. Dillard, Robert H. Soriano, \\ Dikla G. Roufa \\ Department of Anatomy and Cell Biology, Oklahoma State University Center for Health Sciences, Tulsa, USA \\ Email: ${ }^{*}$ kenneth.miller@okstate.edu
}

Received 28 February 2014; revised 25 March 2014; accepted 22 April 2014

Copyright (C) 2014 by authors and Scientific Research Publishing Inc.

This work is licensed under the Creative Commons Attribution International License (CC BY). http://creativecommons.org/licenses/by/4.0/

(c) (i) Open Access

\begin{abstract}
Many medial septal neurons of the basal forebrain are dependent on nerve growth factor (NGF) from the hippocampus for survival and maintenance of a cholinergic phenotype. When deprived of their source of NGF by axotomy, medial septal neuronal cell bodies atrophy and lose their cholinergic markers. This is similar to what is observed in the basal forebrain during Alzheimer's disease (AD). In the present study, medial septal neurons were axotomized in female rats by way of a fimbria/fornix lesion. For fourteen days following axotomy, varying NGF doses (1 $-250 \mu \mathrm{g} / \mathrm{ml})$ were administered to the lateral cerebral ventricle with either mini-osmotic infusion or daily injection. The responsiveness of medial septal neurons was evaluated with choline acetyltransferase immunohistochemistry. Within the mini-osmotic pumps, NGF activity diminished greatly during the first five days of implantation, but increased dramatically in the CSF after five days of infusion. The responsiveness of medial septal neurons to NGF was dose dependent and the $\mathrm{ED}_{50}$ for NGF injection was determined to be $14.08 \mu \mathrm{g} / \mathrm{ml}$ compared to $27.60 \mu \mathrm{g} / \mathrm{ml}$ for NGF infusion. Intermittent injections at varying intervals were evaluated with $30 \mu \mathrm{g} / \mathrm{ml} \mathrm{NGF}$ over a fourteen-day time period $(2,3,6$, or 12 injections). No differences occurred in the number of choline acetyltransferase neurons from rats that received weekly injections to those that received daily injections of NGF. NGF administration has been suggested as a therapy for $\mathrm{AD}$. The results of these studies continue to highlight the need for NGF stability within the delivery system and AD patient CSF, the choice of delivery system, frequency of administration, and the NGF dose for maintaining basal forebrain cholinergic neurons during AD.
\end{abstract}

${ }^{*}$ Corresponding author.

How to cite this paper: Miller, K.E., et al. (2014) Intermittent vs Continuous Administration of Nerve Growth Factor to Injured Medial Septal Cholinergic Neurons in Rat Basal Forebrain. Neuroscience \& Medicine, 5, 109-118. 


\section{Keywords}

\section{Nerve Growth Factor, Medial Septal Nucleus, Choline Acetyltransferase, Alzheimer's, Fimbria, Fornix}

\section{Introduction}

In the rat, medial septal/diagonal band (MS/DB) neurons of the basal forebrain establish connections with the hippocampal formation in late embryonic (E18-19) development [1] [2]. Basal forebrain cholinergic neurons develop from the ventral pallium [3] and are responsive to nerve growth factor (NGF) during development [4] [5]. NGF is synthesized for release by pyramidal neurons of the hippocampus and granule cells of the dentate gyrus [6] [7]. Once synaptic connections have been established, MS/DB neuronal terminals uptake and retrogradely transport NGF to neuronal cell bodies for survival and maintenance of cholinergic phenotype [8].

During Alzheimer's disease (AD), plaques and tangles in the hippocampus disrupt the production, release, and uptake of NGF causing the atrophy and cell death of MS/DB cholinergic neurons [9]. Diminished acetylcholine release from MS/DB nerve terminals exacerbates the altered synaptic function of the hippocampal formation leading to a decline in consolidation of memories. Cholinesterase inhibitors, therefore, are a common therapy for AD [8] [9]. Exogenously supplied or gene-therapy delivered NGF has been proposed as alternative therapies for preservation of MS/DB neurons, maintenance of cholinergic function in the hippocampus, and attenuation of the progression of $\mathrm{AD}[10]-[12]$.

Similar to AD, medial septal (MS) neurons in rodents are deprived of their source of NGF following fimbria/ fornix (FF) lesions causing MS neuronal atrophy and loss of cholinergic markers [13]-[15]. Exogenously supplied NGF rescues and maintains lesioned MS neurons and their cholinergic phenotype [16]-[18]. Many studies have used constant infusion or intermittent injection of NGF into the lateral ventricles after FF transection in rats [19] [20]. Dose response studies for infused NGF have been completed for MS neurons [21]-[24], but no direct comparison of the NGF dose responses for continuous infusion versus intermittent injections has been performed. In the current study, we evaluated the dose effect of NGF using daily intracerebroventicular (ICV) injections versus continuously infusion with mini-osmotic pumps for maintaining MS cholinergic neurons following a FF lesion. MS neurons were evaluated using immunohistochemistry for choline acetyltransferase (ChAT). After determining the NGF dose response for intermittent injections, we evaluated the frequency of NGF injections for maintaining injured MS neurons.

\section{Materials and Methods}

\subsection{Animals}

Female Sprague-Dawley rats (180 - 200 g) were used in this study. Animals were maintained on a $12 \mathrm{hr}$ lightdark cycle and provided with continuous access to food and water. A total of 105 animals were used in this study. These studies were performed at the University of Oklahoma Health Sciences Center (OUHSC) and all procedures were approved by the OUHSC Institutional Animal Care and Use Committee (\#90-135).

\subsection{Fimbria/Fornix Lesion}

All instruments and tubing were sterilized with steam or with $70 \%$ alcohol overnight. Animals were anesthetized with halothane. The head was shaved with an electric razor and placed in a stereotaxic unit. The scalp was swabbed with betadine and a midline incision was made to expose the skull. The overlying connective tissue was scraped and a drop of hydrogen peroxide was placed on the bone to enhance the appearance of bregma. The skull was dried with sterile gauze pads. A hole was drilled $-1.0 \mathrm{~mm}$ from bregma and 1.0 lateral with a $1.80 \mathrm{~mm}$ diameter Trepan bur attached to a Dremel drill. The FF along with overlying cerebral cortex and corpus callosum was aspirated at a depth of $5 \mathrm{~mm}$ with a modified Pasteur pipette attached by rubber tubing to a side arm vacuum flask. Gel foam was placed in the skull hole.

\subsection{Intracerebroventricular (ICV) Cannulation}

Following FF lesioning, a small hole was drilled in the skull with a hand held twist drill at $1.5 \mathrm{~mm}$ lateral to 
bregma, rostral to the lesion hole. A cannula (see below) was inserted $4 \mathrm{~mm}$ through the hole into the lateral ventricle. A small hole was drilled into each parietal bone with a hand held twist drill and sterile stainless steel screws were screwed into the bone for anchoring dental acrylic. Activated dental acrylic was applied over the cannula and screws and allowed to dry. The scalp incision was closed with $9 \mathrm{~mm}$ wound clips and betadine was applied to the incision. The animals were removed from the stereotaxic unit, placed on a heating pad, and allowed to recover consciousness (5 - 10 minutes) after surgery. Afterwards, the animals were returned to their cages for two weeks.

\subsection{Continuous Infusion with Mini-Osmotic Pumps}

Mini-osmotic pumps (Alzet model 2002, flow rate $0.5 \mu \mathrm{l} / \mathrm{hr}, 14$ day duration) were prepared the night before surgery. The pumps were filled with a dose of mouse NGF (5 - $250 \mu \mathrm{g} / \mathrm{ml}$; D88 NGF-006, gift from Monsanto Co., St. Louis, MO) or cytochrome c (100 $\mu \mathrm{g} / \mathrm{ml}$; Sigma Chemical Company, St. Louis, MO) dissolved in artificial cerebrospinal fluid (ACSF) with $0.01 \%$ rat albumin. Solutions were filter sterilized using Costar Spin-X centrifuge filters $(0.22 \mu \mathrm{m}$; Corning Life Sciences, Tewksbury, MA). Silicone rubber tubing (2 cm) was attached and the pumps were placed overnight in a beaker of sterile saline and 2 - 3 drops of betadine. After the cannula hole was drilled in the skull, the free end of the rubber tubing was attached to an L-shaped metal cannula (Small Parts, Inc., Miami, FL) and the cannula was inserted $4 \mathrm{~mm}$ into the lateral ventricle. The connective tissue under the skin of the back was spread with forceps and the pump was placed under the skin. Acrylic was applied over the skull and the incision sutured as described above. The pumps administered NGF or cytochrome c over a two week period ( $\mathrm{n}=5$ /group; $\mathrm{n}=30$ total).

\subsection{Intermittent Injection}

A $4 \mathrm{~cm}$ cannula was made from PE-20 tubing (BD Intramedic, Clay Adams, Parsippany, NJ). A collar of parafilm was made $4 \mathrm{~mm}$ from one end to prevent tubing from going too deep into the lateral ventricle. The other end was heat sealed with a soldering gun. The cannula was placed in $70 \%$ ethanol overnight. After a hole had been drilled in the skull, the cannula was placed into the lateral ventricle, acrylic applied, and the incision sutured. The sealed end of the cannula remained exposed through the incision for ICV injections over the two week period. For injections, the exposed end was cut and $5 \mu \mathrm{l}$ of NGF solution (NGF in ACSF) was injected into the tubing with a $10 \mu \mathrm{l}$ Hamilton syringe (Hamilton Company, Reno, NV). The syringe was removed and $5 \mu \mathrm{l}$ of ACSF was injected with a separate Hamilton syringe to flush the cannula. The cut end was heat sealed with a soldering gun. This was repeated every other day throughout a two week period. When subsequent injections are made, the animals were restrained in a cloth towel. Injections with $1-90 \mu \mathrm{g} / \mathrm{ml}$ concentrations of NGF or 100 $\mu \mathrm{g} / \mathrm{ml}$ of cytochrome c were delivered daily over a two week period (days 0 - 11; $\mathrm{n}=5$ /group; $\mathrm{n}=35$ total).

After determining an NGF dose response for intermittent injection, another set of rats ( $\mathrm{n}=5$ /group; $n=25$ total) was evaluated for the timing of intermittent injections of NGF. The NGF dose used for this study was 30 $\mu \mathrm{g} / \mathrm{ml}$, approximately $2 \times$ the $\mathrm{ED}_{50}$ concentration from the dose response curve. Animals received fimbria/fornix (FF) lesions and immediately were administered NGF into the lateral ventricle. NGF was administered into the lateral cerebral ventricle by intermittent injection with a 14 day survival. Four groups for the following injection regimens were formed: two injections-days 0,7 ; three injections—days $0,6,12$; six injections-days $0,2,4,6$, 8, 10, 12; twelve injections-days 0 - 11 .

\subsection{Immunohistochemistry}

After two weeks of ICV administration of NGF or cytochrome c, the animals were anesthetized deeply with sodium pentobarbitol (60 mg/kg). The thorax was opened and the animal was transcardially perfused, first with $100 \mathrm{ml}$ of saline followed by $400 \mathrm{ml}$ of $2 \%$ paraformaldehyde, $2 \%$ picric acid in $0.1 \mathrm{M}$ phosphate buffer, pH 7.2. The brain was removed and placed overnight in fixative $\left(4^{\circ} \mathrm{C}\right)$. A coronal slab of brain tissue containing the basal forebrain was obtained with the use of a Precision Brain Slicer (Braintree Scientific, Braintree, MA). The brain tissue was affixed to a metal block with adhesive and placed into the water bath compartment of a Vibratome. The medial septum of the basal forebrain was sectioned at $60 \mu \mathrm{m}$, collected with a brush, and placed into a 6-well culture plate in phosphate buffered saline (PBS). Sections were washed in PBS three times for 10 min each, incubated in $10 \%$ phenylhydrazine $\left(37^{\circ} \mathrm{C}\right)$ for $1 \mathrm{hr}$, and washed in PBS for 30 min. Tissue sections were 
incubated in $10 \%$ normal rabbit serum for $1 \mathrm{hr}$ and placed for $48 \mathrm{hrs}\left(4^{\circ} \mathrm{C}\right)$ in choline acetyltransferase (ChAT) antiserum (1:2000; Chemicon, Temeculca, CA). Antisera and normal sera were diluted in PBS with $0.3 \%$ Triton $\mathrm{X}-100$. After $48 \mathrm{hrs}$, the tissue was washed in PBS and processed with avidin-biotin immunohistochemistry. The sections were placed on gelatin coated slides and dried. The sections were dehydrated in an ascending series of ethanols, cleared in xylenes, and coverslips were apposed with Permount.

\subsection{Morphometry}

All cell counting analyses were performed using Zeiss Axiophot microscope with a $10 \times$ objective. At this magnification, the medial septum from the lesioned side could be evaluated in 10 - 15 optical fields. Five sections from the medial septum (rostral to the anterior commissure) were used for quantification: one rostral, two middle, and two caudal sections. Neurons were counted with the aid of a Bioquant image analysis system (Nashville, $\mathrm{TN}$ ). For each animal in every group, the total number of neurons in 5 sections was taken as a single value and these values were averaged for each group. These data were used to produce dose response curves and for calculation of $\mathrm{ED}_{50}$.

\subsection{Data Analysis of MS ChAT Neurons}

Groups were expressed as the mean \pm SEM from individual animals. Statistical analysis included one-way ANOVA for group differences and Newman Keuls post-hoc test to assess individual group differences between control and lesioned animals.

\subsection{PC12 Cells and NGF Evaluation}

We also determined the amount of NGF activity in the cerebrospinal fluid (CSF) and mini-osmotic pumps from a group of non-injured rats that received continuous NGF infusion ( $n=3 /$ time point; $n=15$ total). NGF (250 $\mu \mathrm{g} / \mathrm{ml}$ ) was infused into the lateral ventricle of unlesioned rats via mini-osmotic pumps (Alzet 2002, $0.5 \mu \mathrm{l} / \mathrm{hr}$ ). The ACSF was removed from the mini-osmotic pumps and the CSF was removed from the cisterna magna of rats at $0,1,5,10$, or 14 days. Diluted ACSF or CSF fluid was applied to adrenal pheochromocytoma PC12 cells and the neurotrophic activity of the fluid was assayed by examining the length of neuritic extensions of PC12 cells.

PC12 cells were grown in T150 sterile flasks with filter tops (Corning) and used in bioassay between the PD and P28 passage. Cells were removed from their growth flasks by addition of $25 \mathrm{ml}$ of a $0.05 \%$ trypsin, 0.53 mM EDTA solution (Gibco, Grand Island, NY) for 2 - 4 min and then manually dislodged from the bottom. PC12 cells were plated on diluted rat tail collagen (1:10 with sterile water) on 96-well Costar microtiter plates (Corning) at a density of approx. 15,000 cells/100pl media/well and grown for 24 hrs prior to sample addition. A standard curve for mouse NGF activity was generated by adding known concentrations of serially diluted mNGF to wells $(10 \mathrm{ng} / \mathrm{ml}, 5 \mathrm{ng} / \mathrm{ml}$ down to $0.3 \mathrm{ng} / \mathrm{ml}$ ) in triplicate. Neurite length was determined using a semi-quantitative microscopic evaluation.

The amount of NGF-like activity present in experimental samples was determined by adding serial dilutions of the samples to wells and measuring the PC12 neuritic outgrowth relative to the mNGF standard curve. Serial dilutions were performed by adding $25 \mu \mathrm{l} /$ well in a 96 well Half-Area plate (Costar) of PC12 media consisting of Dulbecco's Minimal Essential Media, $10 \%$ fetal calf serum, $5 \%$ horse serum. Samples were added to the first well at $25 \mu$ land serial dilutions were performed. The resulting materials were transferred to the wells containing the cells at $10 \mu \mathrm{l} /$ well for 1:10 final dilution. Cultures were assayed after 2 - 4 days.

\section{Results}

\subsection{NGF Activity in CSF and Mini-Osmotic Pumps}

By assessing neurite extension from PC12 cells, the NGF biological activity was evaluated from mini-osmotic pumps and CSF of uninjured rats at $0,1,5,10$, and 14 days (Figure 1). The NGF activity in the mini-osmotic pumps was reduced by $70 \%$ at 5 days and was negligible by fourteen days (Figure 1). The concentration of NGF activity in the CSF increased slowly over five days and then increased dramatically until fourteen days. A plateau for NGF biological activity was not reached during this time frame. 


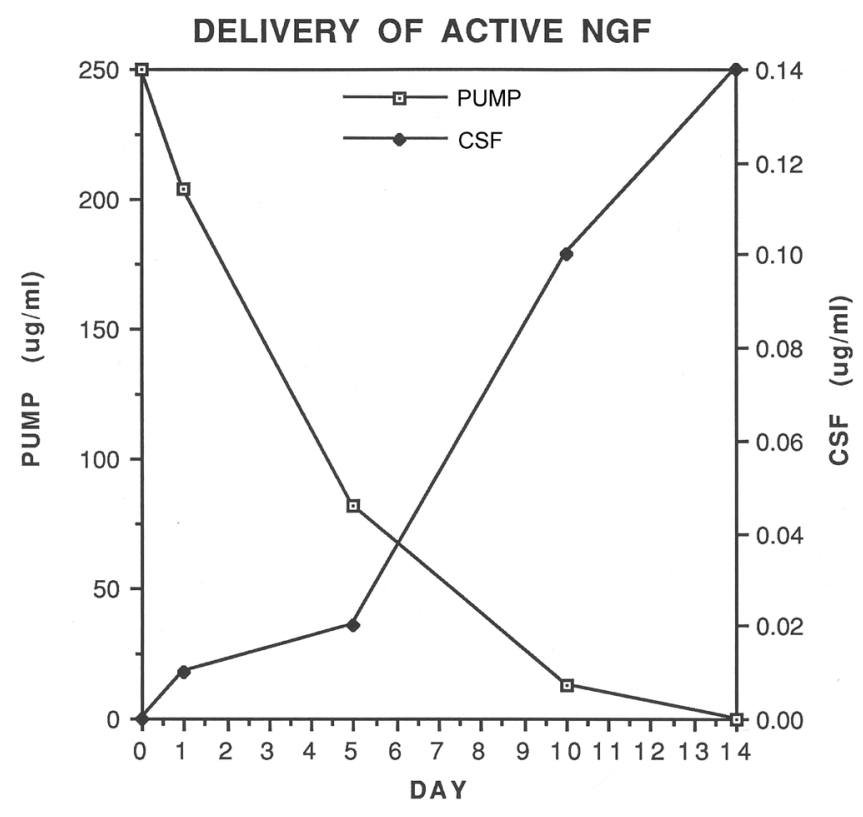

Figure 1. The NGF biological activity was evaluated both from mini-osmotic pumps and CSF of uninjured rats at $0,1,5,10$, and 14 days. The NGF activity (open squares) in the pumps was reduced by $70 \%$ at 5 days and was not detected by fourteen days. In comparison, the NGF activity in the CSF (closed squares) increased slowly over five days and rapidly increased from five to fourteen days.

\subsection{NGF Dose Response Following FF Lesions}

In all cases, rats that received FF lesions were immediately administered NGF or cytochrome C into the lateral ventricle. NGF $(1-250 \mu \mathrm{g} / \mathrm{ml})$ was administered into the lateral cerebral ventricle by continuous infusion using mini-osmotic pumps or intermittent injection, 12 injections with 14 day duration. ChAT-immunoreactive (ChAT-ir) neurons (Figure 2) were counted in the MS and totaled from 5 sections (1 rostral, 2 middle, and 2 caudal sections). Unlesioned rats averaged approximately 600 neurons per five sections (Figure 3). An FF lesion with cytochrome $\mathrm{C}$ administration (control group) caused an $80 \%$ reduction of ChAT-ir neurons (125 neurons per five sections; Figure 3). Administration of $>90 \mu \mathrm{g} / \mathrm{ml}$ NGF by either intermittent injection or continuous infusion returned the number of ChAT-ir neurons to near normal levels (90\%; Figure 4). The responsiveness to NGF was dose dependent $(1-250 \mu \mathrm{g} / \mathrm{ml})$, but showed clear differences between injection vs infusion administrations. The dose response curve for NGF injection was shifted to the left compared to the dose response curve for NGF infusion. Furthermore, the $\mathrm{ED}_{50}$ for NGF injection was $14.08 \mu \mathrm{g} / \mathrm{ml}$ as opposed to 27.60 $\mu \mathrm{g} / \mathrm{ml}$ for NGF infusion.

\subsection{Timing of Intermittent NGF Injections Following FF Lesions}

The timing of intermittent injections was studied by using a $30 \mu \mathrm{g} / \mathrm{ml}$ dose of NGF, approximately $2 \mathrm{x}$ the $\mathrm{ED}_{50}$ concentration from intermittent injection, dose response study. Animals received fimbria/fornix (FF) lesions and immediately were administered NGF into the lateral ventricle. A dose of $30 \mu \mathrm{g} / \mathrm{ml}$ NGF was administered into the lateral cerebral ventricle by intermittent injection (2, 3, 6, or 12 injections) with a 14 day survival. A total of 300 - 400 ChAT-ir neurons were detected in five MS sections from animals with this dosing regimen. No significant differences were seen among the groups with FF lesions and varying intermittent NGF injections (Figure 3).

\section{Discussion}

Nerve growth factor (NGF) is a neurotrophic factor produced by hippocampal and dentate neurons that maintains 

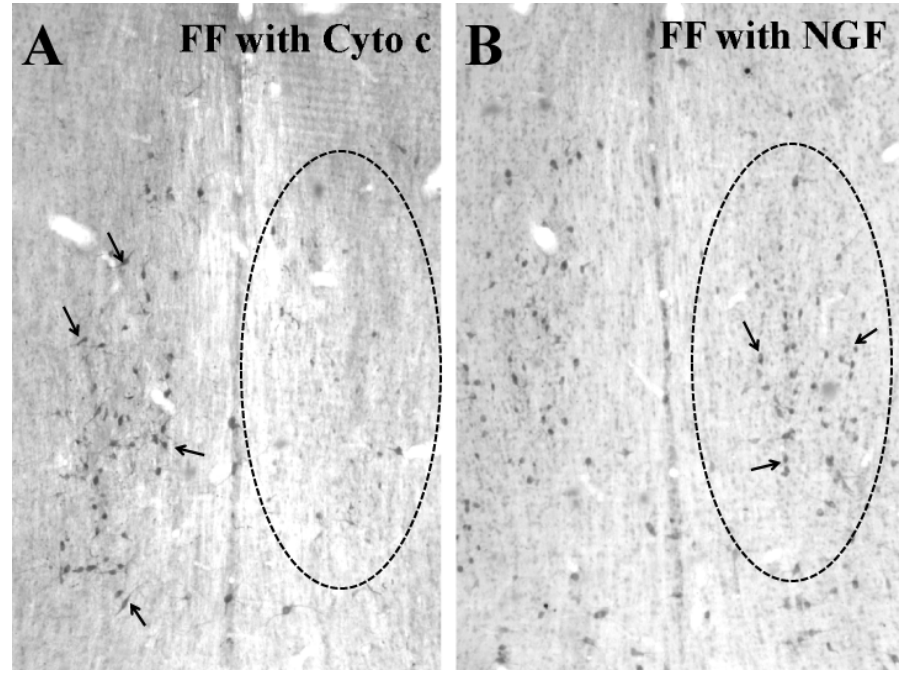

Figure 2. Choline acetyltransferase (ChAT) immunoreactive neurons (arrows) were identified in the medial septum with peroxidase immunohistochemistry. In A, ChAT immunoreactive neurons are largely absent (oval) in the medial septum fourteen days after fimbria-fornix (FF) lesion followed by cytochrome c administration to the lateral cerebral ventricle. In B, ChAT immunoreactive neurons (arrows) are retained (oval) in the medial septum fourteen days after fimbria/fornix (FF) lesion and continuous NGF infusion $(125 \mu \mathrm{g} / \mathrm{ml})$.

\section{NGF Intermittent Injection}

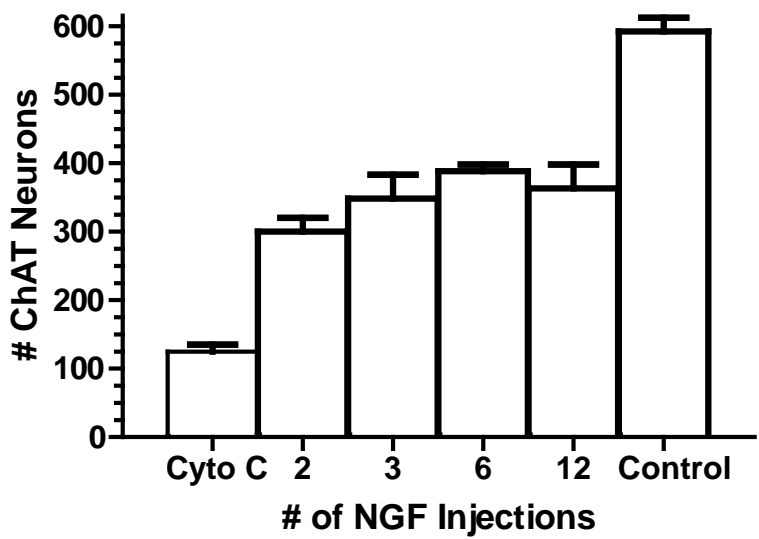

Figure 3. Rats with FF lesions were injected with $30 \mu \mathrm{g} / \mathrm{ml}$ of NGF at the time of axotomy. The total number of $30 \mu \mathrm{g} / \mathrm{ml} \mathrm{NGF}$ injections varied over a 14 day time period: $2,3,6$, or 12 . ChAT immunoreactive neurons ranged between 300 - 400 cells for the various injection regimens. No significant differences were seen among the groups with FF lesions and varying intermittent NGF injections (Figure 3).

the cholinergic phenotype and/or survival of medial septal (MS) neurons. After fimbria/fornix (FF) lesioning in the rat, MS neurons atrophy and decrease the production of cholinergic markers, e.g., choline acetyltransferase (ChAT) [15]. Exogenous NGF promotes the phenotype and survival of injured cholinergic MS neurons [20] [22]. In order to further understand NGF's neurotrophic effects on FF-lesioned MS neurons, the present study evaluated three topics: 1) the amount of NGF in the CSF infused by mini-osmotic pumps was evaluated at several time points during a fourteen day time period; 2) the dose response to NGF in injured MS neurons was compared 


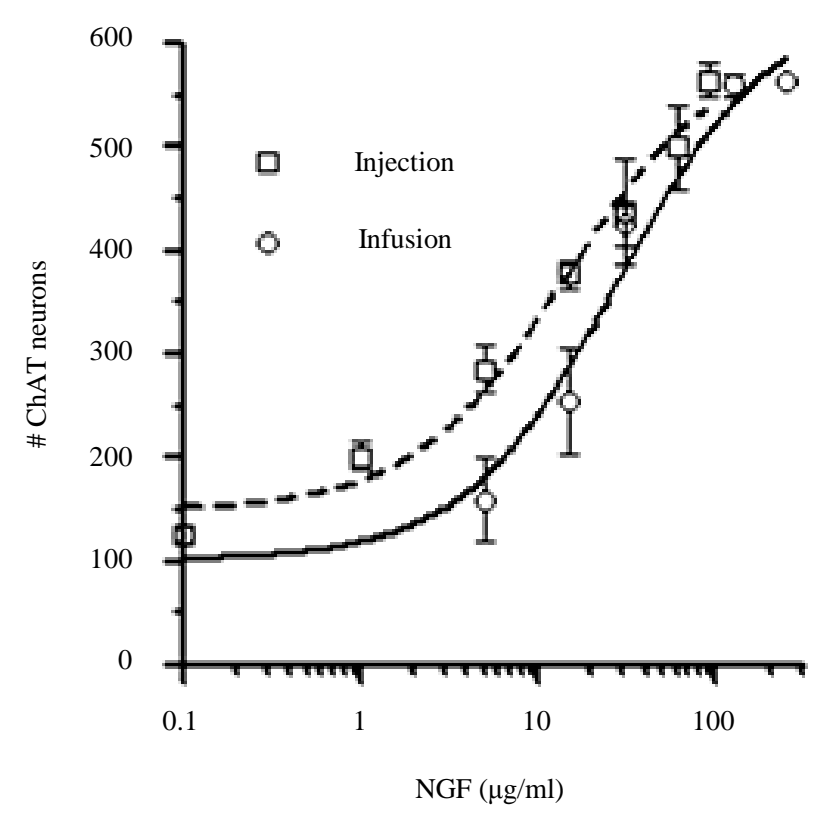

Figure 4. Animals received fimbria/fornix (FF) lesions and were administered NGF immediately. NGF was administered into the lateral cerebral ventricle by continuous infusion (open circles, full line) or intermittent injection (12 injections; open squares, dashed line) over a fourteen day period. ChAT immunoreactive neurons were totaled from five tissue sections of the MS. Unlesioned rats averaged approximately 600 neurons. An FF lesion with cytochrome c administration (control group) caused an $80 \%$ reduction of ChAT immunoreactive neurons compared to unlesioned rats. Administration of $100 \mu \mathrm{g} / \mathrm{ml}$ NGF by either intermittent injection or continuous infusion returned the number of ChAT neurons close to normal levels (>90\%). MS neurons responded to NGF in a dose dependent manner $(1-250 \mu \mathrm{g} / \mathrm{ml})$, but there were differences between injection vs infusion application. The dose response curve for NGF injection was shifted to the left compared to the dose response curve for NGF infusion. The $\mathrm{ED}_{50}$ for NGF injection was $14.08 \mu \mathrm{g} / \mathrm{ml}$ and $27.60 \mu \mathrm{g} / \mathrm{ml}$ for NGF infusion.

using the infusion method versus a daily injection administration; 3) the response of injured MS neurons was evaluated with varying intervals of NGF injections over a fourteen day time period.

Intracerebroventricular (ICV) administration of NGF has been proposed for several decades as a treatment for Alzheimer's disease (AD) and clinical trials with NGF delivered by ICV administration have been performed [25]-[27]. MS neurons atrophy and die during AD due to diminished synthesis, release, uptake, and transport of NGF. Exogenous NGF treatment during AD may maintain the survival of MS neurons, promote cholinergic neurotransmission in the hippocampal formation, and attenuate the progression of $\mathrm{AD}$ [26]. In AD patients, it will be important to maintain a constant therapeutic dose of NGF over long periods of time. Our results show that infusion of NGF into the CSF causes a significant rise in NGF levels over a two week period. With miniosmotic pumps, there is a latency period of several days before substantial amounts of NGF are present in the CSF. This latency period could be overcome in AD patients with an initial bolus administration of NGF or with a scalable infusion system. Furthermore, the biological stability of NGF in an external device also is important to consider [28]. Our results from a fourteen day study indicate that NGF activity drops considerably over a five day period and continues to diminish over the remaining nine days. Stabilization of NGF or ease of refilling an external device will be of concern for delivering NGF with biological activity [28]. 
Comparison of two types of NGF administration can help to characterize the dose effectiveness of NGF for lesioned MS neurons [24]. In our study, daily injection of NGF was more effective than the mini-osmotic infusion. The injection regime yielded an $\mathrm{ED}_{50}$ for NGF of $14.08 \mu \mathrm{g} / \mathrm{ml}$ compared $27.60 \mu \mathrm{g} / \mathrm{ml}$ for infusion. The infusion $\mathrm{ED}_{50}$ differs from an earlier study $(10 \mu \mathrm{g} / \mathrm{ml})$ and may be due to the source of mouse NGF or the stability of the NGF in the mini-osmotic pump [22]. Comparison of the dose response curves for injection of NGF vs infusion indicated that efficacy was better with intermittent infusion (leftward curve and lower $\mathrm{ED}_{50}$ ). This may be due to the instability of NGF in the pumps or the amount of time that was needed to achieve optimal levels of NGF in the CSF. Nevertheless, pulsatile administration appears to be an effective mode of NGF delivery for injured MS neurons. With a lower $\mathrm{ED}_{50}$, intermittent injection may obviate negative NGF effects in $\mathrm{AD}$ patients [25].

Varying the timing between NGF injections did not alter the number of ChAT-ir neurons in the MS. It was surprising that 2 - 3 injections per fourteen days were as effective as daily NGF injections. In rats receiving 2 - 3 injections, NGF's biological activity may have been maintained sufficiently in the CSF for several days or it may be that injured MS neurons do not require a continuous supply of NGF for maintaining their cholinergic phenotype. Although ChAT-immunoreactivity did not change with weekly versus daily NGF injections, it is not known if other aspects of cellular metabolism are altered by the weekly compared to daily injections.

\section{Conclusion}

The results from these studies allow us to make several conclusions. Administration of NGF to the CSF by either injection or infusion is dose dependent for maintaining axotomized cholinergic neurons. If NGF is to be used as a therapy for $\mathrm{AD}$, then either route of administration could be used. Infusion of NGF into the CSF causes a significant rise in NGF levels over a two-week period. In AD patients, it may be possible to maintain a constant therapeutic dose of NGF over long periods of time. Injections of NGF seem to have long lasting effects on axotomized cholinergic neurons in that weekly injections of NGF were as effective as daily injections over a two-week period. AD patients may not need NGF application on continuous or a day-to-day basis, but weekly or biweekly administration may be sufficient.

\section{References}

[1] Linke, R. and Frotscher, M. (1993) Development of the Rat Septohippocampal Projection: Tracing with DiI and Electron Microscopy of Identified Growth Cones. Journal of Comparative Neurology, 332, 69-88. http://dx.doi.org/10.1002/cne.903320106

[2] Linke, R., Pabst, T. and Frotscher, M. (1995) Development of the Hippocamposeptal Projection in the Rat. Journal of Comparative Neurology, 351, 602-616. http://dx.doi.org/10.1002/cne.903510409

[3] Pombero, A., Bueno, C., Saglietti, L., Rodenas, M., Guimera, J., Bulfone, A. and Martinez, S. (2011) Pallial Origin of Basal Forebrain Cholinergic Neurons in the Nucleus Basalis of Meynert and Horizontal Limb of the Diagonal Band Nucleus. Development, 138, 4315-4326. http://dx.doi.org/10.1242/dev.069534

[4] Hess, C. and Blozovski, D. (1990) Intrahippocampal Injection of NGF Accelerates Spontaneous Alteration Ontogenesis and the Maturation of Septohippocampal Cholinergic Innervation in Rats. Comptes Rendus de l'Académie des Sciences-Series III, 310, 533-538.

[5] Mobley, W.C., Rutkowski, J.L., Tennekoon, G.I., Gemski, J., Buchanan, K. and Johnston, M.V. (1986) Nerve Growth Factor Increases Choline Acetyltransferase Activity in Developing Basal Forebrain Neurons. Molecular Brain Research, 387, 53-62. http://dx.doi.org/10.1016/0169-328X(86)90020-3

[6] Whittemore, S.R., Friedman, P.L., Larhammar, D., Persson, H., Gonzalez-Carvajal, M. and Holets, V.R. (1988) Rat Beta-Nerve Growth Factor Sequence and Site of Synthesis in the Adult Hippocampus. Journal of Neuroscience Research, 20, 403-410. http://dx.doi.org/10.1002/jnr.490200402

[7] Bandtlow, C.E., Meyer, M., Lindholm, D., Spranger, M., Heumann, R. and Thoenen, H. (1990) Regional and Cellular Codistribution of Interleukin 1 Beta and Nerve Growth Factor mRNA in the Adult Rat Brain: Possible Relationship to the Regulation of Nerve Growth Factor Synthesis. The Journal of Cell Biology, 111, 1701-1711. http://dx.doi.org/10.1083/jcb.111.4.1701

[8] Schliebs, R. and Arendt, T. (2006) The Significance of the Cholinergic System in the Brain during Aging and in Alzheimer's Disease. Journal of Neural Transmission, 113, 1625-1644. http://dx.doi.org/10.1007/s00702-006-0579-2

[9] Schliebs, R. (2005) Basal Forebrain Cholinergic Dysfunction in Alzheimer's Disease-Interrelationship with BetaAmyloid, Inflammation and Neurotrophin Signaling. Neurochemical Research, 30, 895-908. 
http://dx.doi.org/10.1007/s11064-005-6962-9

[10] Cattaneo, A. and Calissano, P. (2012) Nerve Growth Factor and Alzheimer's Disease: New Facts for an Old Hypothesis. Molecular Neurobiology, 46, 588-604. http://dx.doi.org/10.1007/s12035-012-8310-9

[11] Cattaneo, A., Capsoni, S. and Paoletti, F. (2008) Towards Non Invasive Nerve Growth Factor Therapies for Alzheimer's Disease. Journal of Alzheimer's Disease, 15, 255-283.

[12] Rafii, M.S., Baumann, T.L., Bakay, R.A., Ostrove, J.M., Siffert, J., Fleisher, A.S., Herzog, C.D., Barba, D., Pay, M., Salmon, D.P., Chu, Y., Kordower, J.H., Bishop, K., Keator, D., Potkin, S. and Bartus, R.T. (2014) A Phase1 Study of Stereotactic Gene Delivery of AAV2-NGF for Alzheimer's Disease. Alzheimer's \& Dementia: The Journal of the Alzheimer's Association, 1-11. pii: S1552-5260(13)02838-0. http://dx.doi.org/10.1016/j.jalz.2013.09.004

[13] Gage, F.H., Wictorin, K., Fischer, W., Williams, L.R., Varon, S. and Bjorklund, A. (1986) Retrograde Cell Changes in Medial Septum and Diagonal Band Following Fimbria-Fornix Transection: Quantitative Temporal Analysis. Neuroscience, 19, 241-255. http://dx.doi.org/10.1016/0306-4522(86)90018-7

[14] O’Brien, T.S., Svendsen, C.N., Isacson, O. and Sofroniew, M.V. (1990) Loss of True Blue Labelling from the Medial Septum Following Transection of the Fimbria-Fornix: Evidence for the Death of Cholinergic and Non-Cholinergic Neurons. Brain Research, 508, 249-256. http://dx.doi.org/10.1016/0006-8993(90)90403-X

[15] Gilmor, M.L., Counts, S.E., Wiley, R.G. and Levey, A.I. (1998) Coordinate Expression of the Vesicular Acetylcholine Transporter and Choline Acetyltransferase Following Septohippocampal Pathway Lesions. Journal of Neurochemistry, 71, 2411-2420. http://dx.doi.org/10.1046/j.1471-4159.1998.71062411.x

[16] Gage, F.H., Armstrong, D.M., Williams, L.R. and Varon, S. (1988) Morphological Response of Axotomized Septal Neurons to Nerve Growth Factor. Journal of Comparative Neurology, 269, 147-155. http://dx.doi.org/10.1002/cne.902690112

[17] Gu, H., Long, D., Song, C. and Li, X. (2009) Recombinant Human NGF-Loaded Microspheres Promote Survival of Basal Forebrain Cholinergic Neurons and Improve Memory Impairments of Spatial Learning in the Rat Model of Alzheimer's Disease with Fimbria-Fornix Lesion. Neuroscience Letters, 453, 204-209. http://dx.doi.org/10.1016/j.neulet.2009.02.027

[18] Kromer, L.F. (1987) Nerve Growth Factor Treatment after Brain Injury Prevents Neuronal Death. Science, 235, 214-216. http://dx.doi.org/10.1126/science.3798108

[19] Koliatsos, V.E., Applegate, M.D., Knusel, B., Junard, E.O., Burton, L.E., Mobley, W.C., Hefti, F.F. and Price, D.L. (1991) Recombinant Human Nerve Growth Factor Prevents Retrograde Degeneration of Axotomized Basal Forebrain Cholinergic Neurons in the Rat. Experimental Neurology, 112, 161-173. http://dx.doi.org/10.1016/0014-4886(91)90066-L

[20] Williams, L.R., Varon, S., Peterson, G.M., Wictorin, K., Fischer, W., Bjorklund, A. and Gage, F.H. (1986) Continuous Infusion of Nerve Growth Factor Prevents Basal Forebrain Neuronal Death after Fimbria Fornix Transection. Proceedings of the National Academy of Sciences of the United States of America, 83, 9231-9235. http://dx.doi.org/10.1073/pnas.83.23.9231

[21] Emmett, C.J., Aswani, S.P., Stewart, G.R., Fairchild, D. and Johnson, R.M. (1995) Dose-Response Comparison of Recombinant Human Nerve Growth Factor and Recombinant Human Basic Fibroblast Growth Factor in the Fimbria Fornix Model of Acute Cholinergic Degeneration. Brain Research, 673, 199-207. http://dx.doi.org/10.1016/0006-8993(94)01414-D

[22] Williams, L.R., Jodelis, K.S. and Donald, M.R. (1989) Axotomy-Dependent Stimulation of Choline Acetyltransferase Activity by Exogenous Mouse Nerve Growth Factor in Adult Rat Basal Forebrain. Brain Research, 498, $243-256$. http://dx.doi.org/10.1016/0006-8993(89)91103-7

[23] Williams, L.R., Inouye, G., Cummins, V. and Pelleymounter, M.A. (1996) Glial Cell Line-Derived Neurotrophic Factor Sustains Axotomized Basal Forebrain Cholinergic Neurons in Vivo: Dose-Response Comparison to Nerve Growth Factor and Brain-Derived Neurotrophic Factor. Journal of Pharmacology and Experimental Therapeutics, 277, 11401151.

[24] Vahlsing, H.L., Hagg, T., Spencer, M., Conner, J.M., Manthorpe, M. and Varon, S. (1991) Dose-Dependent Responses to Nerve Growth Factor by Adult rat Cholinergic Medial Septum and Neostriatum Neurons. Brain Research, 552, 320329. http://dx.doi.org/10.1016/0006-8993(91)90098-G

[25] Eriksdotter Jonhagen, M., Nordberg, A., Amberla, K., Backman, L., Ebendal, T., Meyerson, B., Olson, L., Seiger, Shigeta, M., Theodorsson, E., Viitanen, M., Winblad, B. and Wahlund, L.O. (1998) Intracerebroventricular Infusion of Nerve Growth Factor in Three Patients with Alzheimer's Disease. Dementia and Geriatric Cognitive Disorders, 9, 246-257. http://dx.doi.org/10.1159/000017069

[26] Aloe, L., Rocco, M.L., Bianchi, P. and Manni, L. (2012) Nerve Growth Factor: From the Early Discoveries to the Potential Clinical Use. Journal of Translational Medicine, 10, 239. http://dx.doi.org/10.1186/1479-5876-10-239 
[27] Olson, L., Nordberg, A., Von Holst, H., Backman, L., Ebendal, T., Alafuzoff, I., Amberla, K., Hartvig, P., Herlitz, A., Lilja, A., et al. (1992) Nerve Growth Factor Affects 11C-Nicotine Binding, Blood Flow, EEG, and Verbal Episodic Memory in an Alzheimer Patient (Case Report). Journal of Neural Transmission-Parkinson's Disease and Dementia Section, 4, 79-95. http://dx.doi.org/10.1007/BF02257624

[28] Allen, S.J., Robertson, A.G., Tyler, S.J., Wilcock, G.K. and Dawbarn, D. (2001) Recombinant Human Nerve Growth Factor for Clinical Trials: Protein Expression, Purification, Stability and Characterisation of Binding to Infusion Pumps, Journal of Biochemical and Biophysical Methods, 47, 239-255. http://dx.doi.org/10.1016/S0165-022X(01)00134-8 